Results While the stimulation indices (SI) in the healthy control group ranged from 0.5 to 3.5 (mean SI: $1.5 \pm 0.9$ ), the proliferative response of PBMC of the patient group ranged from 0.7 to 17 with a mean SI of $4.8 \pm 4.0$ (only 6 of 34 patients had an SI $<2 ; \mathrm{p}<0.00004)$. The generated 30 TCC derived from SLE patients and 19 TCC from healthy controls did not reveal a significant difference in SI and produced either more IFNg than IL4 or none of these cytokines at all, suggesting that these TCC were of T1 or T0, but not T2 phenotype. Interestingly though, while only $11 \%$ of healthy control patients showed a CD4-/ $\mathrm{CD}^{+}{ }^{+}$subtype and $16 \%$ displayed a $\mathrm{CD} 4^{+} / \mathrm{CD}^{+}$phenotype, $37 \%$ of TCC derived from SLE patients were CD4-/CD ${ }^{+}$(and $20 \%$ expressed CD4 as well as CD8).

Conclusion Our data reveal that more than $80 \%$ of SLE-patients have a significant $\mathrm{T}$ cell reactivity $(\mathrm{SI}>2$ ) to the nuclear protein hnRNP-A2/B1 indicating that the antibody response might be $\mathrm{T}$ cell driven. Furthermore, almost $60 \%$ of TCC derived from SLE patients were $\mathrm{CD} 8^{+}$, which supports the importance of these $\mathrm{T}$ cells in SLE. Further studies will have to elucidate the pathogenetic implications of these findings.

\section{FRI0087 ANAEMIA IN SYSTEMIC LUPUS ERYTHEMATOSUS}

${ }^{1} \mathrm{P}$ Athanassiou, ${ }^{2} \mathrm{E}$ Griva, ${ }^{3} \mathrm{I}$ Kostoglou-Athanassiou, ${ }^{1} \mathrm{~A}$ Elezoglou, ${ }^{4} \mathrm{~S}$ Papazoglou, ${ }^{5} \mathrm{D}$ Rontogianni, ${ }^{1} \mathrm{G}$ Vezyroglou, ${ }^{4} \mathrm{~T}$ Kontomerkos. ${ }^{1}$ Department of Rheumatology, Asklepieion Hospital, Voula; ${ }^{2}$ Department of Haematology; ${ }^{3}$ Department of Endocrinology, Metaxa Hospital, Pireaus, Greece; ${ }^{4}$ Department of Rheumatology; ${ }^{5}$ Department of Histopathology, General Hospital of Athens "G. Gennimatas", Athens

\subsection{6/annrheumdis-2001.1229}

Background Systemic lupus erythematosus (SLE) is accompanied by haematological abnormalities. A very common haematological abnormality observed in SLE is anaemia. It is well known that anaemia in SLE may have many causes, however no correlation has been performed between anaemia and the morphology of red blood cell precursors in the bone marrow in SLE.

Objectives The aim was to investigate the aetiology of anaemia in SLE by analysing blood, bone marrow aspirate and bone marrow biopsy findings.

Methods SLE patients were included in the study, $\mathrm{n}=17$, aged $40.9 \pm 3.6$ (range 18-36) years. None of the patients were taking any disease modifying agents and 11 were newly diagnosed and had never taken any treatment for SLE, duration of disease of the remaining being $5.7 \pm 3.6$ (range 1-23) years. In all patients antinuclear antibodies, anti-DNA antibodies and serum rheumatoid factor were measured. Haematocrit, haemoglobin, $\mathrm{MCV}, \mathrm{MCH}, \mathrm{MCHC}$, serum iron, serum ferritin, serum ironbinding capacity, serum folate and vitamin B12 levels were also measured and indirect and direct Coombs' test was performed. In all patients a bone marrow aspirate was obtained and a bone marrow biopsy was performed.

Results In 17 SLE patients haemoglobin levels were $11.4+0.4 \mathrm{~g} /$ $\mathrm{dl}$ (mean $\pm \mathrm{SEM}$ ), haematocrit $35.0 \pm 1.3 \%$, MCV $88.9 \pm 1.2$ $\mathrm{fl}, \mathrm{MCH} 29.0 \pm 0.4 \mathrm{pg}, \mathrm{MCHC} 32.7 \pm 0.1 \%$, serum iron levels $83.2 \pm 7.2 \mathrm{?g} / \mathrm{dl}$, serum iron-binding capacity $359.0 \pm 11.2 \mathrm{?g} /$ $\mathrm{dl}$, ferritin levels $123.1 \pm 65.3 \mathrm{?g} / \mathrm{dl}$, folate $6.4 \pm 1.1 \mathrm{ng} / \mathrm{ml}$ and vitamin B12 levels $534.7 \pm 79.4 \mathrm{pg} / \mathrm{ml}$. In 10 of 17 patients with SLE haemoglobin levels were $12 \mathrm{~g} / \mathrm{dl}$, hyperplasia of red blood cell precursors was noted in all of them, megaloblastoid alterations in 3 and blasts of the red cell series in 2 patients. No correlation was observed between the presence or absence of anaemia and the dysplastic alterations in the red blood cell precursors in the bone marrow in the SLE patients studied.
Conclusion The aetiology of anaemia in SLE patients seems to be multifactorial. Dysplastic alterations in red blood cell precursors was noted in all the groups of SLE patients, irrespective of the presence of anaemia, indicating either a primary defect of the stem cell in the bone marrow in SLE which is implicated in the pathogenesis of the disease or that inflammatory cytokines may affect the microenvironment of the bone marrow.

\section{FRI0088 POLY(ADP-RIBOSE) POLYMERASE (PARP) POLYMORPHISM IN SPANISH SYSTEMIC LUPUS ERYTHEMATOSUS (SLE) PATIENTS}

${ }^{1} \mathrm{~T}$ Martin-Donaire, 'MJ Citores, 'S Rosado-Garcia, ${ }^{2}$ Rua-Figueroa, ${ }^{3} \mathrm{I}$ Garcia-Laorden, ${ }^{2} \mathrm{C}$ Rodriguez-Lozano, ${ }^{1} \mathrm{P}$ Perez-Aciego, ${ }^{3} \mathrm{C}$ Rodriguez-Gallego, ${ }^{4} \mathrm{~A}$ Durantez. 'Laboratorio, Fundacion Lair; ${ }^{2}$ Reumatologia; ${ }^{3}$ Inmunologia, Hospital de Gran Canaria Doctor Negrin, Las Palmas de Gran Canaria, Spain; ${ }^{4}$ Medicina Interna, Clinica Puerta de Hierro, Madrid

\subsection{6/annrheumdis-2001.1230}

Background PARP is a DNA-binding protein that catalyses the covalent addition of ADP-ribose to many nuclear proteins. It is involved in DNA repair and apoptosis, processes that have been implicated as causative factors for SLE. It has been shown that patients suffering SLE have decreased PARP mRNA levels and a low enzime activity. The PARP gene is located at 1q41-q42 and contains a microsatellite (CA)n polymorphism in the promoter region that probably affects the transcription and mRNA levels. A recent study found preferential transmission of the allele containing $12 \mathrm{CA}$ repeats to affected offspring in Caucasian SLE families.

Objectives To investigate the association between PARP polymorphism and SLE susceptibility in Spaniards.

Methods 76 unrelated SLE patients from Canary Islands (Spain) fulfilling at least four of the ACR criteria and 79 sex-matched healthy donors were included. A segment of the PARP gene containing the microsatellite was amplified by PCR and the resulting products were electrophoresed in denaturing polyacrilamide gels. Chi-square test was used for statistical analysis.

Results Allelic distributions of PARP polymorphism showed no statistical differences between SLE patients and controls. But considering particular clinical features we found several associations with specific alleles: a) homozygotes for 11rep. allele suffered more lymphopenia $(\mathrm{p}=0.04)$ but less hypocomplementemia $(\mathrm{p}=0.03), \mathrm{b})$ autoantibodies anti-Ro/La were more frequent $(\mathrm{p}=0.02)$ in carriers of 15 rep., c) carriers of 16rep. allele presented more malar rash $(p=0.03)$ and seizures $(p=0.04)$, and finally $d)$ carriers of 17 rep. allele showed a reduced risk of production of several autoantibodies as anti-Sm $(\mathrm{p}=0.007)$ and anti-Ro/La $(\mathrm{p}=0.04)$.

Conclusion Although PARP alleles seem not to influence susceptibility to SLE in Spaniards, some of them may be related to the presence of several clinical and analytical manifestations of the disease.

\section{FRI0089 IL10G PROMOTER POLYMORPHISM OF THE INTERLEUKIN 10 (IL10) IN SPANISH SYSTEMIC LUPUS ERYTHEMATOSUS (SLE) PATIENTS}

'S Rosado-Garcia, 'MJ Citores, 'T Martin-Donaire, ${ }^{2}$ Rua-Figueroa, ${ }^{3}$ I Garcia-Laorden, ${ }^{2} \mathrm{C}$ Rodriguez-Lozano, ${ }^{1} \mathrm{P}$ Perez-Aciego, ${ }^{3} \mathrm{C}$ Rodriguez-Gallego, ${ }^{4} \mathrm{~A}$ Durantez. ${ }^{1}$ Laboratorio, Fundacion Lair; ${ }^{2}$ Reumatologia; ${ }^{3}$ Inmunologia, Hospital de Gran Canaria Doctor Negrin, Las Palmas de Gran Canaria, Spain; ${ }^{4}$ Medicina Interna I, Clinica Puerta de Hierro, Madrid

10.1136/annrheumdis-2001.1231 